\section{Contributors}

Moontarin Ansar is an ST3 and AiT RCGP Representative East of Scotland Deputy UK Council Representative for the Vasco da Gama Movement.

John Brooks is a GP in Congleton, Cheshire.

jbsbrooks@hotmail.co.uk

Mike Fitzpatrick

fitz@easynet.co.uk

Nicolle Green is an ST1 in South Manchester currently working in Care of the Elderly at Wythenshawe hospital, with an interest in the Vasco da Gama movement and the development of foreign exchanges. nicollegreen@yahoo.co.uk

\section{Dougal Jeffries}

dougal6@googlemail.com

Brian Keighley is a GP in Balfron, Stirlingshire.

Bkeighley@aol.com

Edin Lakasing has been a full-time GP in Chorleywood, Hertfordshire. He is a trainer on the Watford Vocational Training Scheme, and undergraduate tutor to University College Hospital and Imperia College, London. In his spare time he writes, mainly on clinical medicine, education, and health service development, and frets over the next Tottenham Hotspur result. edin.lakasing@chorleywoodhealthcentre .nhs.uk

Helen Lester

Helen.Lester@manchester.ac.uk

Luisa Pettigrew is a salaried GP in London and UK Council Representative for the Vasco da Gama Movement.

Jonathan Richards is a GP at Morlais Medical Practice, Dowlais,

Merthyr Tydfil.

qwq46@dsl.pipex.com

Allan James Smith is a GP ST2 Trainee at Castleside Clinic, Dover Health Centre, Dover.

Kenallanjsmith@doctors.org.uk

\section{Richard Smith}

richardswsmith@yahoo.co.uk

\title{
A rose by any other name
}

I first met one of my oldest friends when we'd both reached that waddling stage of pregnancy. It was 1990. I had recently qualified as a GP and she was a partner in a local practice. Our first kids were born 6 days' apart. As our families expanded, between us, we used just about every job scheme going: locum, locum with a view, partner at all sorts of $\%$ shares, salaried GP, retainer, and academic GP with an honorary clinical contract. For years we spent Wednesday afternoons whinging happily about our various practices while the kids leapt across the furniture and scribbled on newly painted walls. We moaned about being on call on Mondays or not being on call on Mondays (depending on how the practice organised the Bank Holiday rota); partners who made a habit of putting chronic visits in the visit book too often; needing but rarely getting extra time for coil fittings. We talked, at times, about the difficulties of being partners with specific practice responsibilities and being parents - but we never, once, whatever our contractual status, needed to moan about exploitation.

There has been a lot of press coverage recently about salaried doctors. In 1998, there were 762 salaried GPs in England, increasing to 6022 in 2007, and by a further $10 \%$ in the last year. The number of principals has remained stable over that time period at around $27500 .^{1}$ The reasons for the increase in salaried posts are complex; the 2004 GP contract is now widely described as the key catalyst for change. Whatever the causes, the practical consequence is a lack of advertised partnerships. The April 1st edition of Pulse reported that $80 \%$ of new vacancies were for salaried posts. Should this matter? Well yes, hugely, and for at least three reasons. First, salaried GPs are far more likely to be female and work part-time. ${ }^{2}$ While this is not a feminist issue, you have at least to raise the spectre of discrimination rather than choice. Secondly, there is a growing financial disparity between salaried doctors and profit sharing principals. Between 2003-2006, salaried GPs received a pay rise of $3 \%$ and principals of $58 \% .^{3}$ Do we really want to support a system of such overt financial disparity? Thirdly, while a salaried post may suit some men and women (and a $£ 70000$ full-time option is a very good wage at any time and particularly at the moment), the lack of partnerships means those who want to take on additional roles and responsibilities are being sidelined, and opportunities to use their manifest talents, squandered.

The RCGP and GPC have recently begun to address these issues through a joint discussion paper on the current state and future shape of GP partnerships. ${ }^{4}$ Drawing on the federated model of primary care described in the RCGP Roadmap, ${ }^{5}$ they suggest that within practice consortia, GPs could work together as teams rather than as salaried doctors or partners. Roles would be based on functions rather than levels of importance, with a basic tripartite structure of the traditional GP who predominantly sees patients, GPs with other interests including leading commissioning, and primary care directors who take responsibility for organisational issues such as finance, workforce and governance. They point out that roles can overlap as much as a practice wants and that salaried doctors could be directors. The financial implications of such arrangements are, however, unclear.

Changing partnerships is an excellent start, highlighting the problems and offering one possible solution. But it is reliant on a model of care that is not widely available. What of the salaried doctors who currently feel disenfranchised, disillusioned, even exploited? While the spectre of private providers is often raised as a stick for effecting change, I think the more important carrot is around professionalism. Many of the current generation of younger doctors are just as excited by the prospect of partnership, of contributing to practice development, of making a difference not just in the consulting room as the principals they work for. Perhaps it's time for a minority of principals to think less about income protection and more about the future of the profession.

\section{REFERENCES}

1. The Health and Social Care Information Centre. NHS Staff 1998-2008 (General Practice). http://www.ic. nhs.uk/statistics-and-datacollections/workforce/nhs-staff-numbers/nhs-staff1998--2008-general-practice (accessed 4 Apr 2009).

2. Ding A, Hann M, Sibbald B. Profile of English Salaried GPs. Br J Gen Pract 2008; 58: 20-25.

3. Kmietowicz Z. Contract for GPs in England failed to live up to expectations. BMJ 2008; 337: a2025.

4. Gerada C. Changing partnerships. London: RCGP, 2009. http://www.rcgp.org.uk/pdf/Changing Partnerships.pdf (accessed Apr 2009).

5. Lakhani M, Baker M, Field S. The future direction of general practice: a roadmap. London: RCGP, 2007.

DOI: 10.3399/bjgp09X420833 